\title{
Patient-Level Exclusions from mHealth in a Safety-Net Health System
}

\author{
Keiki Hinami, MD, MS ${ }^{1 *}$, Bhrandon A. Harris, MD², Ricardo Uriostegui, MD², \\ Wilnise Jasmin, MD, MBA², Mario Lopez, MD², William E. Trick, MD'1
}

${ }^{1}$ Collaborative Research Unit, Department of Medicine, Cook County Health and Hospitals System, Chicago, Illinois; ${ }^{2}$ Department of Family Medicine, Cook County Health and Hospitals System, Chicago, Illinois

\begin{abstract}
Excitement about mobile health (mHealth) for improving care transitions is fueled by widespread adoption of smartphones across all social segments, but new disparities can emerge around nonadopters of technology-based communications. We conducted a cross-sectional survey of urban lowincome adults to assess inadequate reading health literacy and limited English proficiency as factors affecting access to and engagement with mHealth. Although the proportion owning smartphones were comparable to national figures, adjusted analysis showed fewer patients with inadequate reading health literacy having Internet access (odds ratio
\end{abstract}

[95\% confidence interval]: 0.50 [0.26-0.95]), e-mail $(0.43$ [0.24-0.79]), and interest in using e-mail (0.34 [0.18-0.65]) for healthcare communications. Fewer patients with limited English proficiency were interested in using mobile apps (0.2 [0.09-0.46]). Inpatient status was independently associated with less interest in text messaging (0.46 [0.25-0.87]). $\mathrm{mHealth}$ exclusions around literacy and language proficiency threaten equity, and innovative solutions are needed to realize mHealth's potential for reducing disparities. Journal of Hospital Medicine 2017;12:90-93. (C) 2017 Society of Hospital Medicine
Interest in mHealth-the use of mobile communication devices for clinical and public health-has exploded among clinicians and researchers for its potential to efficiently improve patient health. Recent studies have used mHealth's asynchronous receptive and expressive communication functions in interventions targeted to managing care transitions and hospital readmissions. ${ }^{1-3}$ We also recently published on improved readmission risk assessments using postdischarge measures of patient reported outcomes, which could be collected through mobile devices. ${ }^{4}$ But persistent disparities in access to ${ }^{5}$ and engagement with ${ }^{6}$ smartphones may threaten validity and equity when mHealth strategies do not fully address its own limitations.

Disparities introduced by uneven access to technology are well known, but the rapid, albeit belated, adoption of mobile devices by racial minority groups in the United States has allowed authors of recent thoughtful publications to recast mHealth as itself offering solutions to the disparities' problem. ${ }^{7,8}$ Others have cautioned the emergence of disparities along domains other than race, such as low literacy and limited English proficiency (LEP). ${ }^{9}$ In this paper, we assessed the impact of inadequate reading health literacy (IRHL) and LEP on factors related to access and engagement with mHealth. We conducted our study among urban low-income adults in whom IRHL and LEP are common.

\footnotetext{
*Address for correspondence and reprint requests: Keiki Hinami, MD, MS, 1900 W. Polk St., Rm 1412, Chicago IL 60612; Telephone: 312-864-3647; Fax: 312-864-9694; E-mail: khinami@cookcountyhhs.org
}

Received: May 25, 2016; Revised: July 21, 2016; Accepted: July 31, 2016

2017 Society of Hospital Medicine DOI 10.12788/jhm.2686

\section{METHODS}

We surveyed patients in a large public safety-net health system serving 132 municipalities, including the city of Chicago, in northeastern Illinois. In 2015, nearly $90 \%$ of patients were racial-ethnic minorities with more than onethird insured by Medicaid and another one-third uninsured. We sampled adult inpatients and outpatients separately by nonselectively approaching patients in November 2015 to complete an in-person questionnaire in a 464-bed hospital and in 2 primary-care clinics. All inpatients occupied a nonisolation room in a general medical-surgical ward that had been sampled for data collection for that day in 9-day cycles with 8 other similar units. All outpatients in the clinic waiting areas were approached on consecutive days until a predetermined recruitment target was met. Each participant was surveyed once in his/her preferred language (English or Spanish), was 18 years and older, consented verbally, and received no compensation. Sample size provided $80 \%$ power to detect a device ownership rate of $50 \%$ in an evenly allocated low literacy population compared to a reference rate of $66 \%$ assuming a 2 -sided $\alpha$ of 0.05 using the Fisher exact test.

The 18-item questionnaire was informed by constructs addressed in the 2015 Pew Research Center smartphone survey. ${ }^{10}$ However, in addition to device ownership, we inquired about device capabilities, service-plan details, service interruptions due to difficulty paying bills in the previous year, home-Internet access, an active e-mail account, and self-assigned demographics. Self-reported reading health literacy, ${ }^{11}$ more directly measured than e-health literacy, was screened using a parsimonious instrument validated as a dichotomized measure. ${ }^{12}$ Instruments in English and Spanish were tested for appropriate and comprehensible word choices and syntax through pilot testing. We inferred LEP among patients preferring to complete the survey in Spanish based 
on our familiarity with the population. We defined any Internet access as having a mobile data-service plan or having home-Internet access. In addition, we inquired about primary insurance provider and offered Medicaid patients an informational brochure about the federal Lifeline Program (https://www.fcc.gov/lifeline) that subsidizes text-messaging-enabled cellular telephone service for low-income patients. Notably, we assessed engagement by asking about the extent of patients' interest in "new ways of communicating with your doctor, clinic, or pharmacy using" text, e-mail, or mobile apps with a 5-level response scale ranging from "not at all interested" to "very interested".

Participant characteristics were confirmed to be similar to the Cook County Health and Hospitals System patient population in 2015 with regards to age, gender, and race/ethnicity. We calculated unadjusted and adjusted odds ratios for IRHL and LEP's association with each dependent measure of access (to smartphone, Internet, or e-mail) and engagement (using text messaging, e-mail, or mobile apps) controlling for age, gender, primary payer, recruitment location, IRHL, and LEP. Because we oversampled inpatients, we estimated sampling-weight-adjusted proportions and $95 \%$ confidence intervals (CI) of the entire CCHHS patient population with access to smartphone, data/text plan, non-prepaid plan, and service interruptions using STATA v13 (StataCorp LP, College Station Texas). The project received a waiver upon review by the local Institutional Review Board.

\section{RESULTS}

Participation rate was 65\% (302/464). Differences in patients by site are shown in Table 1 . IRHL was more frequent and LEP less frequent among hospitalized patients. As shown in Table 2, patients with IRHL were less likely to have any Internet access, to have an active e-mail account, and to be interested in using e-mail for healthcare communications. Patients with LEP were less likely than English speakers to be interested in using mobile apps. Inpatients were less likely than outpatients to be interested in text messaging for healthcare communications.

The estimated proportion $(95 \% \mathrm{CI})$ of the health system's patients owning a text-enabled mobile device was $87 \%$ (75\%-94\%) and an Internet-enabled mobile device was $64 \%(47 \%-78 \%)$. The proportion with no data service interruptions in the previous year was $40 \%$ (31\%-50\%).

\section{DISCUSSION}

In this cross-section of urban low-income adult patients, IRHL and LEP were factors associated with potential disparities introduced by mHealth. Even as access to smartphones becomes ubiquitous, lagging access to Internet and e-mail among low literacy patients, and low levels of technology engagement for healthcare communications among patients with IRHL or LEP, underscore concerns about equity in health systems' adoption of mHealth strategies. Hospitalized patients were found to have diminished engagement with mHealth independent of IRHL and LEP.
TABLE 1. Characteristics of Patients Recruited from an Urban Safety-Net Healthcare System in November 2015 and Their Access to and Engagement with mHealth by Recruitment Site

\begin{tabular}{|c|c|c|}
\hline & Inpatient & Outpatient \\
\hline N & 100 & 202 \\
\hline \multicolumn{3}{|l|}{ Age category, n (\%) } \\
\hline $18-30$ & $10(10)$ & $37(18)$ \\
\hline $31-50$ & $30(30)$ & $57(28)$ \\
\hline $51-65$ & $48(48)$ & $76(38)$ \\
\hline$>65$ & $12(12)$ & $32(16)$ \\
\hline Women, n (\%) & $37(37)$ & $133(66)$ \\
\hline \multicolumn{3}{|l|}{ Race-ethnicity category, n (\%) } \\
\hline Non-Hispanic black & $57(57)$ & $102(50)$ \\
\hline Latino & $26(26)$ & $97(48)$ \\
\hline Non-Hispanic white & $11(11)$ & $3(1)$ \\
\hline Other & $6(6)$ & $0(0)$ \\
\hline US citizen, n (\%) & $71(71)$ & $132(65)$ \\
\hline \multicolumn{3}{|l|}{ Primary payer, n (\%) } \\
\hline Self-pay & $49(49)$ & $75(37)$ \\
\hline Medicaid or dual eligible & $28(28)$ & $97(48)$ \\
\hline Medicare & $8(8)$ & $12(6)$ \\
\hline Private & $6(6)$ & $14(7)$ \\
\hline Other & $9(9)$ & $4(2)$ \\
\hline Positive inadequate health literacy screen, $n(\%)$ & $47(47)$ & $70(35)$ \\
\hline LEP Spanish speakers, n (\%) & $20(20)$ & $101(50)$ \\
\hline \multicolumn{3}{|l|}{ Ownership of mobile device functionality, $n$ (\%) } \\
\hline Text messaging & 95 (95) & $179(89)$ \\
\hline Internet & $56(56)$ & $128(63)$ \\
\hline Uninterrupted data service plan, $n$ (\%) & $33(33)$ & $87(43)$ \\
\hline Active e-mail account, $\mathrm{n}(\%)$ & $49(49)$ & $115(57)$ \\
\hline Any Internet access, n (\%) & $74(74)$ & $142(70)$ \\
\hline Interest in text for healthcare communications, $\mathrm{n}(\%)$ & $65(65)$ & $95(47)$ \\
\hline Interest in e-mail for healthcare communications, $n$ (\%) & $42(42)$ & $80(40)$ \\
\hline Interest in apps for healthcare communications, n (\%) & $24(24)$ & $54(27)$ \\
\hline
\end{tabular}

Regarding engagement, significantly fewer patients with IRHL or LEP were interested in using technology for healthcare communications. Our finding suggests that health disparities already associated with these condition $s^{13}$ may not be reduced by mobile device outreach alone and may even be worsened by it. Touch screens, audio-enabled questionnaires, and language translation engines are innovations that may be helpful to mitigate IRHL and LEP, but evidence is scarce. Privacy and security concerns, and lack of experience with technology, may also lower engagement. A contemporaneous study found lower apps' usage among Latinos, also suggesting that language concordance between apps, their source, and targeted users is important..$^{14}$ Lowtech solutions involving mobile telephone or even lower tech in-person communications targeted to the estimated $26 \%$ of the US population with low literacy ${ }^{15}$ and $20 \%$ with LEP ${ }^{16}$ may be practical stopgap measures. Even as disparities 
TABLE 2. ORs and $95 \% \mathrm{Cls}$ for IRHL, LEP, and Inpatient Status Associated with Technology Access and Engagement Controlling for Age, Gender, and Primary Payer

\begin{tabular}{|c|c|c|c|c|c|c|c|c|c|}
\hline & \multicolumn{3}{|c|}{ Inadequate health literacy } & \multicolumn{3}{|c|}{ Limited English proficiency } & \multicolumn{3}{|c|}{ Inpatient } \\
\hline & $\begin{array}{l}\text { Unadjusted } \\
\text { Odds Ratio }\end{array}$ & $\begin{array}{l}\text { Adjusted } \\
\text { Odds Ratio }\end{array}$ & $P$ & $\begin{array}{l}\text { Unadjusted } \\
\text { Odds Ratio }\end{array}$ & $\begin{array}{c}\text { Adjusted } \\
\text { Odds Ratio }\end{array}$ & $P$ & $\begin{array}{l}\text { Unadjusted } \\
\text { Odds Ratio }\end{array}$ & $\begin{array}{c}\text { Adjusted } \\
\text { Odds Ratio }\end{array}$ & $P$ \\
\hline Access to a smartphone & $\begin{array}{c}0.26 \\
(0.11-0.61)\end{array}$ & $\begin{array}{c}0.40 \\
(0.16-1.03)\end{array}$ & 0.06 & $\begin{array}{c}0.40 \\
(0.18-0.88)\end{array}$ & $\begin{array}{c}0.55 \\
(0.18-1.69)\end{array}$ & 0.30 & $\begin{array}{c}0.41 \\
(0.15-1.11)\end{array}$ & $\begin{array}{c}0.35 \\
(0.11-1.13)\end{array}$ & 0.08 \\
\hline Any internet access & $\begin{array}{c}0.30 \\
(0.18-0.51)\end{array}$ & $\begin{array}{c}0.50 \\
(0.26-0.95)\end{array}$ & 0.03 & $\begin{array}{c}0.60 \\
(0.36-1.00)\end{array}$ & $\begin{array}{c}1.04 \\
(0.48-2.25)\end{array}$ & 0.93 & $\begin{array}{c}0.83 \\
(0.48-1.43)\end{array}$ & $\begin{array}{c}0.74 \\
(0.36-1.53)\end{array}$ & 0.41 \\
\hline Active email account & $\begin{array}{c}0.26 \\
(0.16-0.42)\end{array}$ & $\begin{array}{c}0.43 \\
(0.24-0.79)\end{array}$ & $<0.01$ & $\begin{array}{c}0.62 \\
(0.39-0.98)\end{array}$ & $\begin{array}{c}0.89 \\
(0.45-1.79)\end{array}$ & 0.75 & $\begin{array}{c}1.38 \\
(0.85-2.23)\end{array}$ & $\begin{array}{c}1.38 \\
(0.71-2.66)\end{array}$ & 0.34 \\
\hline $\begin{array}{l}\text { Interested in using text } \\
\text { messaging }\end{array}$ & $\begin{array}{c}0.72 \\
(0.45-1.14)\end{array}$ & $\begin{array}{c}1.29 \\
(0.70-2.37)\end{array}$ & 0.41 & $\begin{array}{c}0.48 \\
(0.30-0.77)\end{array}$ & $\begin{array}{c}0.62 \\
(0.33-1.18)\end{array}$ & 0.15 & $\begin{array}{c}0.48 \\
(0.29-0.78)\end{array}$ & $\begin{array}{c}0.46 \\
(0.25-0.87)\end{array}$ & 0.02 \\
\hline Interested in using email & $\begin{array}{c}0.25 \\
(0.15-0.42)\end{array}$ & $\begin{array}{c}0.34 \\
(0.18-0.65)\end{array}$ & $<0.01$ & $\begin{array}{c}0.60 \\
(0.37-0.96)\end{array}$ & $\begin{array}{c}0.99 \\
(0.51-1.91)\end{array}$ & 0.98 & $\begin{array}{c}0.91 \\
(0.56-1.47)\end{array}$ & $\begin{array}{c}0.74 \\
(0.39-1.41)\end{array}$ & 0.36 \\
\hline $\begin{array}{l}\text { Interested in using } \\
\text { mobile apps }\end{array}$ & $\begin{array}{c}0.53 \\
(0.30-0.93)\end{array}$ & $\begin{array}{c}1.36 \\
(0.68-2.75)\end{array}$ & 0.38 & $\begin{array}{c}0.29 \\
(0.16-0.54)\end{array}$ & $\begin{array}{c}0.20 \\
(0.09-0.46)\end{array}$ & $<0.01$ & $\begin{array}{c}1.16 \\
(0.66-2.01)\end{array}$ & $\begin{array}{c}0.74 \\
(0.47-1.49)\end{array}$ & 0.40 \\
\hline
\end{tabular}

NOTE: Abbreviations: Cl, confidence interval; IRHL, inadequate reading health literacy; LEP, limited English proficiency; OR, odds ratio.

in access to technology across race-ethnicity are diminishing, ${ }^{10}$ equity across poverty levels, low levels of education, cultural norms, and disabilities may be more challenging to overcome. Our assessment indicates that large exclusions of a safety-net population in 2015 are a legitimate concern in communication strategies that rely too heavily on mHealth. These findings underscore the CONSORT-EHEALTH recommendation that investigators report web-based recruitment strategies and data-collection methods comprehensively. ${ }^{17}$

Regarding access, our estimates suggest that historical disparities in smartphone ownership are diminishing, but access to Internet capabilities may still be lower among the urban poor compared to the nation as a whole. The Pew Research Center found that $64 \%$ of Americans owned a smartphone in 2015 (respondents defined smartphone).$^{10}$ In comparison, $87 \%$ (95\% CI, $75 \%, 94 \%)$ of our study participants owned a text-enabled mobile device and $64 \%(47 \%, 78 \%)$ owned an Internet-enabled mobile device. However, the 40\% (31\%, $50 \%$ ) of our safety-net population with an uninterrupted data plan over the previous year may be lower than the 50\% of Americans reporting uninterrupted data plans over their lifetime. ${ }^{10}$ The impact of expense-related data plan interruptions is magnified by the $40 \%$ of our study population-compared to $15 \%$ of Americans - who are dependent on mobile devices for Internet access. ${ }^{10}$ The association between Internet connectivity and literacy evokes multiple bidirectional pathways yet to be elucidated. But if mHealth can reduce health disparities, closing the gap in device ownership is only a partial accomplishment, and future work also needs to expand Internet connectivity to allow literacy-enhancing and literacy-naïve technologies to flourish.

This study has limitations. Our study population was a consecutive sample and participation rate was less than $100 \%$. However, we recruited participants into the study the way we may also have approached patients to intro- duce mHealth options in our clinical settings. Our sampling method proved adequate for our primary goal to explain differences in technology access and engagement using regression analysis. Although our patient population may not directly generalize to many healthcare systems, including other safety-net systems serving regions with variable technology uptake, ${ }^{18}$ our findings reflect the capacities and the preferences of the most disadvantaged segments of urban populations. We systematically excluded LEP non-Spanish speakers, but they consisted of less than $5 \%$ of inpatients and no outpatients. We did not assess current technology use. Finally, as discussed earlier, access and use of new technologies change rapidly and frequent updates are necessary.

$\mathrm{mHealth}$ is a promising tool because it may increase healthcare access, improve care quality, and promote research. All these potential benefits will be obtained with accompanying efforts to reduce healthcare disparities, especially where some technologies themselves are exclusionary. ${ }^{9}$ As research of mHealth methods grows, support for patients with IRHL and LEP are still necessary to simultaneously advance our shared goal for equity.

Disclosures: The authors report no financial conflicts of interest.

\section{References}

1. Khosravi P, Ghapanchi AH. Investigating the effectiveness of technologies applied to assist seniors: a systematic literature review. Int J Med Inform. 2016;85: $17-26$.

2. Feltner C, Jones CD, Cené CW, et al. Transitional care interventions to prevent readmissions for persons with heart failure: a systematic review and meta-analysis. Ann Intern Med. 2014;160:774-784.

3. Prieto-Centurion V, Gussin HA, Rolle AJ, Krishnan JA. Chronic obstructive pulmonary disease readmissions at minority-serving institutions. Ann Am Thorac Soc. 2013;10:680-684

4. Hinami K, Smith J, Deamant CD, BuBeshter K, Trick WE. When do patient-reported outcome measures inform readmission risk? J Hosp Med. 2015;10:294-300.

5. Gibbons MC. A historical overview of health disparities and the potential of eHealth solutions. J Med Internet Res. 2005;7:e50.

6. Nelson LA, Mulvaney SA, Gebretsadik T, Ho YX, Johnson KB, Osborn CY. Dis- 
parities in the use of a mHealth medication adherence promotion intervention for low-income adults with type2 diabetes. J Am Med Inform Assoc. 2016;23:12-18.

7. Martin T. Assessing mHealth: opportunities and barriers to patient engagement. J Health Care Poor Underserved. 2012;23:935-941.

8. Horn IB, Mendoza FS. Reframing the disparities agenda: a time to rethink, a time to focus. Acad Pediatr. 2013;14:115-116.

9. Viswanath K, Nagler RH, Bigman-Galimore CA, McCauley MP, Jung M, Ramanadhan $\mathrm{S}$. The communications revolution and health inequalities in the 21st century: implications for cancer control. Cancer Epidemiol, BiomarkersPrev. 2012;21:1701-1708.

10. Pew Research Center. The Smartphone Difference. Pew Research Center; April 2015. Available at: http://www.pewinternet.org/2015/04/01/us-smartphone-usein-2015/. Accessed January 12, 2017.

11. Baker DW. The meaning and measure of health literacy. J Gen Intern Med. 2011;21:878-883

12. Morris NS, MacLean CD, Chew LD, Littenberg B. The single item literacy screener: evalution of a brief instrument to identify limited reading ability. BMC Fam Pract. 2006;7:21.
13. Sentell T, Braun K. Low health literacy, limited English proficiency, and health status in Asians, Latinos, and other racial/ethnic groups in California. J Health Commun. 2012;17:82-99.

14. Arora S, Ford K, Terp S, et al. Describing the evolution of mobile technology usage for Latino patients and comparing findings to national mHealth estimates. $J$ Am Med Inform Assoc. 2016;23:979-983.

15. Paasche-Orlow MK, Parker RM, Gazmararian JA, Nielsen-Bohlman LT, Rudd RR. The prevalence of limited health literacy. J Gen Intern Med. 2005;20:175-184.

16. US Census Bureau. Detailed languages spoken at home and ability to speak English for the population 5 years and over: 2009-2013. Published 2015. Available at: http://www.census.gov/data/tables/2013/demo/2009-2013-lang-tables.html. Accessed March 31, 2016.

17. Eysenbach G, CONSORT-EHEALTH Group. CONSORT-EHEALTH: improving and standardizing evaluation reports of Web-based and mobile health intervention. J Med Internet Res. 2011;13:e126.

18. Schickedanz A, Huang D, Lopex A, et al. Access, interest, and attitudes toward electronic communication for health care among patients in the medical safety net. J Gen Intern Med. 2013;28:914-920. 